All patients who repeated the questionnaire appeared adherent to TB medication. There were substantial improvements in LCQ responses after a median of $14(10-14)$ days' treatment ( $\mathrm{n}=12$; median [IQR] score 9.1 [8.1-14.5] at baseline, 18.3 [14.5-19.4] at two weeks, median improvement 5.1 [1.8-9.7], $p=0.003$; Figure 1). The effect size of the change in LCQ scores was 1.17 .

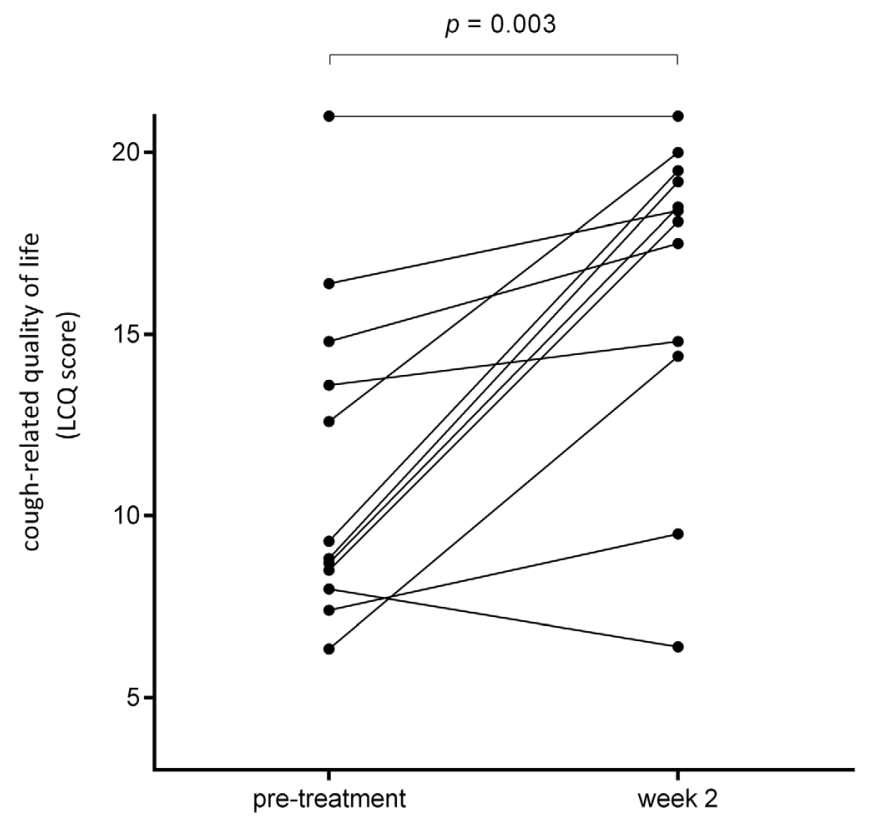

Abstract P240 Figure 1 Changes Leicester Cough Questionnaire score during early treatment of pulmonary tuberculosis

Conclusion The LCQ is a valid instrument for evaluating coughrelated QOL in TB and may be a useful outcome measure to evaluate therapy.

\section{P241 THE FEASIBILITY AND VALIDITY OF OBJECTIVE COUGH MONITORING IN CHILDREN USING AN ADULT COUGH DETECTION SYSTEM}

D Deblej Elghamoudi, H Sumner, K McGuiness, J Smith, CS Murray. University of Manchester, Manchester, UK

\subsection{6/thoraxjnl-2015-207770.377}

Background In young children the evaluation of symptoms is almost wholly reliant upon parental reporting. Cough is extremely common in childhood and a tool to objectively measure cough frequency would be clinically beneficial. To date paediatric cough monitoring systems have relied on manual cough counting which is time consuming and costly. The VitaloJAK $^{\mathrm{TM}}$ (Vitalograph, UK) is a custom built $24 \mathrm{hr}$ semi-automated cough monitoring device that has been used successfully to quantify cough in adults. Using the VitaloJAK ${ }^{\mathrm{TM}}$ we tested the feasibility of $24 \mathrm{hr}$ cough recordings in children and tested existing compression software for cough quantification.

Methods Children (age 2-14 years) with acute or chronic cough were asked to wear VitaloJAK ${ }^{\mathrm{TM}}$ cough monitor for a maximum of $24 \mathrm{~h}$. Feedback about the device was obtained from the child/ carer were appropriate. All recordings were manually counted and also processed through the compression software.
Results 40 children ( 21 male; mean age 8 yrs) wore the monitor for a median of $22.25 \mathrm{~h}(0.38-24 \mathrm{hrs})$. Children who wore the monitor as out-patients with chronic cough generally wore the monitor for longer (median $23.07 \mathrm{hrs}$ ) than those who were in-patients with acute symptoms (median $12.59 \mathrm{hrs;} \mathrm{p}=0.06$ ). Twenty-nine children (73\%) wore the monitor for $>12 \mathrm{~h}$ and 22 for $>22$ hrs including during the night. Eighteen (45\%) children reported the monitor was heavy/bulky and eleven (28\%) said at times it restricted some normal daily tasks (bending/stooping/ using the toilet). Neither length of time the monitor was worn for, nor complaints about the size or restricting nature of the monitor, were age dependent. No serious adverse events were reported. One recording was excluded due to technical problems. Recordings demonstrated wide variability in frequency from 2 to 2712 coughs per recording (median 72). Following compression a median of $98.5 \%(85.7-100)$ of coughs were retained.

Conclusions VitaloJAK ${ }^{\mathrm{TM}}$ semi-automated cough monitor can be used in children to accurately measure cough frequency. As with many medical interventions, it was not tolerated by all children for long periods, however the majority of children were able to wear it for $>12 \mathrm{~h}$.

\section{P242 THE ORDER EFFECT OF EXPERIMENTAL OESOPHAGEAL ACIDIFICATION ON COUGH REFLEX SENSITIVITY IN CHRONIC COUGH PATIENTS AND HEALTHY VOLUNTEERS}

D Valdramidou, H Sumner, E Hilton, S Whiteside, JA Smith. University of Manchester/ University Hospital South Manchester NHS, Manchester, UK

\subsection{6/thoraxjnl-2015-207770.378}

Background One of the mechanisms thought to be involved in the triggering of chronic cough is gastroesophageal reflux. We aimed to compare the effects of oesophageal acid infusion on cough reflex sensitivity in chronic cough (CC) patients with healthy volunteers (HV).

Method In a randomised, double-blind, placebo-controlled, crossover study, $0.15 \mathrm{M}$ hydrochloric acid/saline was infused in the distal oesophagus of each subject. Each infusion treatment was separated by a washout period of at least 7 days. Single dose inhalation capsaicin challenge $\left(\mathrm{C}_{5}\right)$ was used to measure cough reflex sensitivity before (baseline), immediately after $(\mathrm{t}=$ 0 mins) and $90 \mathrm{~min}, 180 \mathrm{~min}$ and $24 \mathrm{hrs}$ post infusion. Data were analysed using Generalised Estimating Equation (GEE) models.

Results Ten CC patients (mean age $56.0 \pm 11.0$ years, 8 females) and twelve HV (mean age $26 \pm 8.3$ years, 7 females) completed the study. Overall, CC patients had a more sensitive cough reflex than HV (geometric mean ratio 0.46; ratio 0.05, Table 1). Furthermore, there was a significant order effect (acid-saline vs saline-acid); CC patients appeared to be sensitised to acid infusion when given first $(\mathrm{p}$-value $=0.039)$, but not second $(\mathrm{p}$-value $=$ 0.245), whereas HV cough responses were not influenced by the infusion order (all p-values $>0.05$ ).

Conclusions In our experience, distal oesophageal acid infusion did not sensitise the cough reflex in either CC patients or HV. Notably, the order of the infusions heavily influenced the cough responses of CC patients compared to HV. Future study designs need to be cognisant of order effects and if cross-over designs are used, test for the presence of these. 
Abstract P242 Table 1 Summary statistics from the fitted model and comparisons between chronic cough patients and healthy volunteers are presented below as adjusted geometric means and the pairwise differences ratios of the adjusted means

\begin{tabular}{|c|c|c|c|c|c|c|}
\hline \multicolumn{7}{|c|}{$C_{5}$ Capsaicin Concentration - Adjusted Means and Difference Ratios between Subject Types } \\
\hline & \multirow{2}{*}{$\begin{array}{l}\text { Chronic Cough Patients }(\mathrm{N}=10) \\
\text { Adjusted Geometric Mean }(\mu \mathrm{M})\end{array}$} & \multirow{2}{*}{$\begin{array}{l}\text { Healthy Volunteers }(\mathrm{N}=12) \\
\text { Adjusted Geometric Mean }(\mu \mathrm{M})\end{array}$} & \multicolumn{4}{|c|}{ Chronic Cough Patients vs. Healthy Volunteers } \\
\hline & & & Geom & Ratio with $95 \% \mathrm{Cl}$ & & pairwise $p$-value \\
\hline Overall & 35.2 & 77.4 & 0.46 & $0.20,1.09$ & 0.078 & \\
\hline \multicolumn{7}{|c|}{ By Infusion Type } \\
\hline Acid & 29.5 & 83.8 & 0.36 & $0.15,0.88$ & 0.025 & \\
\hline Saline & 41.8 & 71.4 & 0.42 & $0.20,0.87$ & 0.019 & \\
\hline \multicolumn{7}{|c|}{ By Infusion Type and Order } \\
\hline \multicolumn{7}{|l|}{ Acid } \\
\hline Acid-Saline & 20.0 & 114.3 & - & - & - & \\
\hline Saline-Acid & 43.5 & 61.3 & - & - & - & \\
\hline $\mathrm{p}$-value & 0.039 & 0.367 & - & - & $\cdot$ & \\
\hline \multicolumn{7}{|l|}{ Saline } \\
\hline Acid-Saline & 30.8 & 105.4 & - & - & - & \\
\hline Saline-Acid & 56.7 & 48.3 & - & - & - & \\
\hline$p$-value & 0.245 & 0.167 & - & - & - & \\
\hline
\end{tabular}

\section{P243 ASSESSING THE EFFECT OF PH ON CITRIC ACID COUGH CHALLENGES IN CHRONIC COUGH PATIENTS AND HEALTHY VOLUNTEERS}

Z Rai, H Fowles, J Howard, A Morice. Hull and East Yorkshire NHS Foundation Trust, Hull, UK

\subsection{6/thoraxjnl-2015-207770.379}

Introduction Citric acid has been used for over 6 decades in cough challenge studies, however despite this, the mechanism of its tussive effect is still not fully understood. We assessed the cough response to citric acid solutions, at different levels of acidity $(\mathrm{pH})$ to determine what role this plays in the induction of cough. Healthy volunteers and chronic cough patients were compared.

Methods 20 chronic cough patients and 20 healthy volunteers were recruited and underwent three cough challenges at $48 \mathrm{~h}$ apart. Each visit involved 5 repeated inhalations of a $300 \mathrm{mM}$ citric acid solution. Whilst the concentration of the citrate cation was kept constant, the $\mathrm{pH}$ was varied by titration with sodium hydroxide, to achieve $\mathrm{pH} \mathrm{3,5}$ and 6 . These represent the Pka values of the individual acid moieties within citric acid. The total number of coughs elicited per study day was recorded.

\section{Mean Number of Coughs in Chronic Coughers} and Healthy Volunteers

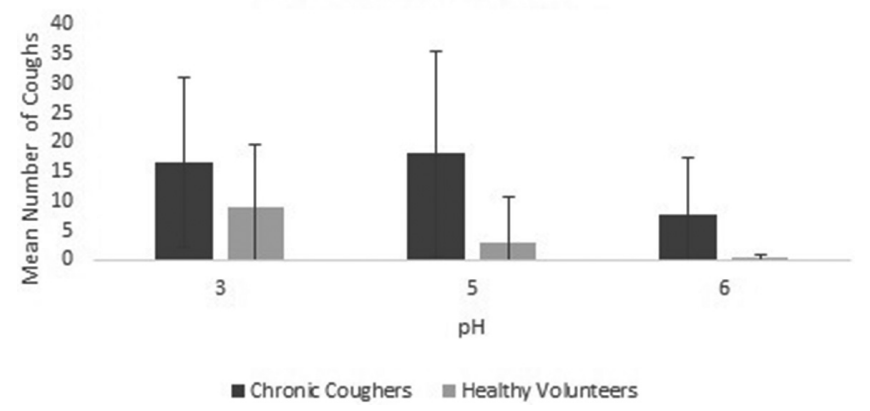

Abstract P243 Figure 1
Results Participants were gender matched, each group consisting 12 females Two participants withdrew and were not included in the analysis. In healthy volunteers, $60 \%$ of people coughed at $\mathrm{pH} 3$ (average coughs 9), 30\% of people coughed at pH5 (average coughs 3 ), and $10 \%$ of people coughed at $\mathrm{pH} 6$ (average coughs 0 ). In contrast, $74 \%$ of chronic coughers coughed at $\mathrm{pH} 3$ (average coughs 16), 89\% coughed at $\mathrm{pH} 5$ (average coughs 18) and $63 \%$ coughed at $\mathrm{pH} 6$ (average coughs 7 ). Thus there was a clear dose response to decreasing $\mathrm{pH}$ in healthy volunteers but not in chronic cough patients. The standard deviation of cough challenge on an individual day was determined to explore the variability of response to inhalation challenge. At $\mathrm{pH} 3 \mathrm{CC}$ vs $\mathrm{HV}$ was $\mathrm{x}$ vs $\mathrm{y}$, at $\mathrm{pH} 5 \times 1$ vs $\mathrm{y} 1$ and at $\mathrm{pH} 6 \times 2$ vs $\mathrm{y} 2(\mathrm{p}>0.01)$.

Discussion As we have previously reported, chronic cough patients are hypersensitive to citric acid challenge. However the response to individual challenge is much more variable than in $\mathrm{HV}$, suggesting the cough reflex circuitry in these patients is 'unstable'. This was particularly shown at higher $\mathrm{pH}$ where cough was virtually abolished in healthy volunteers but not chronic cough patients. It has been widely suggested that cough hypersensitivity resides in up regulation and interplay of different peripheral receptors. That a single stimulus increases the variability of response in a pathological state suggests that hypersensitivity to citric acid resides in a complex central rather than peripheral mechanism.

\section{Asthma quality improvement}

\section{P244 \\ THE IMPACT OF "SEVEN DAY WORKING" ON RESPIRATORY INPATIENT ACTIVITY AT ST HELENS AND KNOWSLEY NHS TRUST. - "THE SLOW DRIFT MODEL"}

S Twite, P Stockton, V Sreeguru Lakshman, P Malhotra, S Alapati, S Koduri, J Naveed, J Howard. St Helens and Knowsley NHS Trust, Prescot, UK

10.1136/thoraxjnl-2015-207770.380 